\title{
Ghosts of the Present Past: Spectrality in the Video Game Object
}

\author{
Justyna Janik
}

The aim of the article is to analyse the phenomenon of ghost characters in video games from the perspective of Jacques Derrida's concept of hauntology, and to use this as the starting point for a hauntological engagement with the video game object's relationship with its own past. The paper will investigate ghostly figures and their spectral status inside the video game environment, as well as their uncertain hauntological status as both fictional bygone souls and digital in-game objects. On the basis of this analysis of ghostly figures in video game environments, I draw a line between the past of the fictional world and the past of the game world, and examine what happens when they overlap. The dual status of the in-game ghost will thereby serve to metonymically anchor an investigation into the duality of the game as a whole, as both fiction and digital materiality, and of the different dimensions of the past that exist in between these two levels of the game object.

Keywords: ghost, past, video game, hauntology, specters.

Ghostly figures are connected to the act of communication. In numerous narratives, such as legends, myths or folk tales, these spectral entities appear as clairvoyant messengers, storytellers or bringers of punishment. However, regardless of function, they always exist in an in-between state: not quite belonging to the realm of the living, but not entirely crossing to the other side either. They are, at the same time, both a sign of the separation between the two different ontological domains - that of the living and that of the dead, the present and the past - and of the proximity of the two domains, which allows them to influence each other across this separation. The main aim of the paper is to see if the ghostly figures that appear in the digital realm of video games can serve as a starting point for uncovering similar structures relating to the presence of the past, in different forms, in relation to the video game object.

\footnotetext{
* The Article was created within the research project PRELUDIUM 14 financed by National Science Centre, Poland (Jagiellonian University 2017/27/N/HS2/00672, „Game as a resistant object. Relationship between the player and the video game in posthuman perspective").
} 
Accordingly, I shall make the case that the presence of ghosts in the video game object carries a significance that goes beyond their being a simple narrative trope. In order to support this claim, I want to analyse the ghostly figures that haunt the fictional worlds of video games, and unveil what their appearance tells us about the nature of the video game object. By using Jacques Derrida's concept of hauntology (1994), I will show how the spectral nature of these ghosts brings forward different modes of the presence of the past in the digital object of the video game, and how they are connected to the experience of fiction, game mechanics and the process of play.

Hauntology, despite its fluctuating borders and vague character, is an approach which might easily be used in the research of various phenomena within contemporary culture, beyond Derrida's original analysis of Marxist specters floating over Europe. In game studies, Christian McCrea (2009) uses Derrida's concept to analyse how horror game environments and gameplay are haunted by other media, such as VHS images an instance of 'spectral remediation' which presents hauntology as a useful analytical tool for new media scholars. Nevertheless, the interpretative potential of hauntology has not yet been fully exploited. This paper addresses this gap in the existing research by using hauntology to uncover spectral relationships between different layers of the video game object.

The first layer I will consider is the fictional world - the diegetic domain of characters, objects, places and events that is represented by the game. The second layer, the game world, emerges from the materiality of the video game object. The game object is, as Olli Tapio Leino (2012) argues, the playable artifact where the processes of the game and its digital materiality are inseparably intertwined. In this context, the game world would be a digital space where the player and the game object communicate with each other, through everything that is specific to a digital artifact: the digital environment, ingame objects with their digital properties, the mechanics of the game, the underlying lines of code, and interfaces.

The tension between the fictional world and the game world layer is rendered clearly visible through the complex nature of the past in video games. I shall start by asking how the appearance of specters impacts the experience of play and our perception of the game object and engage with ghostly figures as these occur as parts of both the digital materiality and the fictional world of video games. Therefore, the paper starts by questioning the ontology of digital ghosts and their spectral status inside the video game environment. By discussing different examples of ghostly apparitions in a number of selected games, I will be able to more closely examine the spectral (in the Derridean sense) nature of video game ghosts and their uncertain (haunt)ological status as both fictional bygone souls and digital in-game objects. This dual state of existence reflects, or rather hides, the tension between the different kinds of past that haunt the video game object. As such, the analysis of video game ghosts will establish a distinction and draw a 
line between the past of the fictional world and the past of the game world, as well as necessitating a closer look at what happens when they overlap. On the conceptual foundation of hauntology, then, I will be able, first, to conduct a spectral analysis of the specific examples of ghost representations in the video games, their properties and functions inside the game object, and, second, to use this as a starting point for the analysis of the past in the realm of digital materiality.

\section{Ghosts and Specters}

To start thinking about the figure of the ghost in the video game, we need to answer the question: what is a ghost? In most cases, when we think about ghosts, we are thinking about beings from the past. They might appear to us as imprints of memory or traces of long-gone beings. We can see this often used in video games to show the player glimpses of past events in the form of prerecorded scenes filled with ghostly figures. In System Shock 2 (Irrational Games, 1999) or BioShock (2K Games, 2007), we can witness short and distorted scenes that help us uncover the mystery of what happened, respectively, on the spaceship Von Braun and in the underwater city of Rapture. However, as clear as their connection to history is, ghosts are not connected so much with events that merely happened in the past as with very private emotions for those who see them. As Ryūnosuke Akutagawa (2009) intimated in his story "In a Grove” (better known from Rashōmon (1950), the film adaptation by Akira Kurosawa), ghosts can lie. Thus, even if ghosts are entities connected to the netherworld, they still behave like flawed human beings. Regardless of these human-like behaviors and familiar features, they first and foremost bring a feeling of anxiety to those who meet them. Haunting tends to be an unpleasant event, especially when it concerns a visit from an unquiet spirit. Most narratives involving ghosts teach us, if not to be afraid of these spectral entities, then at least to feel uneasy around them. However, the unease we are supposed to experience during contact with the souls of the departed is not always linked with fear alone, but also with eeriness. We are not exactly afraid of ghost Boos in Super Mario games, but their trickster-like nature makes encounters with them very different, erratic even, compared with Mario's other enemies. The presence of ghosts always generates the peculiar feeling of the uncanny.

The concept of the uncanny, first theorized by Sigmund Freud (1919/2003), seems to be a perfect tool for analyzing the encounter with a ghost. In both philosophy and psychology, it is often used to describe phenomena that convey a sense of the mystery hidden inside familiar objects and events. Something that is well-known or even close to us suddenly oversteps its proper behavior, and makes us uncertain about our experienced reality. Sometimes even a spark or a sudden change is enough to convert the familiar environment into something strange and weird which needs to be read afresh (Royle 2003, 1-10). As Nicholas Royle notes: "it is perhaps inseparable from an apprehension, 
however fleeting, of something that should have remained secret and hidden but has come to light” (ibid., 2).

We can see that the concept of the uncanny applies in particular to the notion of ghosts. When a ghost is supposed to manifest itself to someone, the thin veil between this world and the spirit world weakens, and secrets of the past and the future are in danger of being revealed. Most stories about ghosts are based on this very premise. In video games, we often meet a vengeful spirit on our way, just to uncover the tragic past that puts its wrong-doing into different perspective. In video games the plot will often have it that it is the player who has to decide what to do with the uncovered secret. This is a case during the "In the Claws of Madness" quest from The Witcher 2: Assassins of Kings (CD Projekt RED, 2011), when the main protagonist of the game, Geralt, is asked to deal with the vengeful ghost of the Nilfgaardian soldier that haunts the ruins of an asylum. When he does so, he finds out that the soldier was the real victim in this story, having been murdered by the quest-givers. As a result, Geralt/the player has to make a decision about what to do with the real murderers: whether to take the human or the ethereal side, or to remain neutral. Reality seems to be in a state of flux.

Such an understanding of the uncanny is clearly conveyed in Jacques Derrida's concept of hauntology, which relies on the notion of the specter. Derrida takes political transformations in Europe as the subject of his analysis in Specters of Marx (1994). In this work, he attempts to show a mechanism thanks to which Karl Marx's philosophy is still present in today's political reality. For that purpose, Derrida creates the methodology of hauntology to describe the things and thoughts which are out of their proper time and place. He explains the phenomenon with the help of a reading of Shakespeare's Hamlet. Especially meaningful for Derrida is the passage in which the Prince of Denmark, devastated by his fate, declaims: "The time is out of joint - $\mathrm{O}$ cursèd spite/ That ever I was born to set it right!” (Derrida 1994, 20-27; Ham. 1.5.190-191). Analysing these words, Derrida aims to grasp the very nature of haunted time. Time ceases to be linear and systematized and becomes heterogeneous, escaping any systematization.

For Derrida, ideas belonging to an earlier time - present to us only as specters - invoke the concept of the past, but paradoxically, at the same time, influence the present. Even if they seem to be nothing more than a simple memory, they have the ability to actively modify the present and thereby change the future. However, the real danger is hiding in the fact that these past ideas and objects are being embraced as present (Marzec 2015, 208-217). One can say that the present is haunted by bygone phenomena that continue to shape reality: "the past refuses to pass away and the future - to arrive" (ibid., 193). Therefore, what we should do as researchers is to focus our analysis on these spectral phenomena, and, by doing this, to expose their influence on our reality.

Another problematic aspect of specters, as Derrida points out, is their uncanniness, which is connected to their uncertain ontological status: they are neither beings nor non- 
beings, not alive but also not exactly dead (Derrida 1994, 4-6). This paradoxical state distinguishes specters from spirits, and, at the same time, evades precise description (or even definition). "Neither soul nor body, and both one and the other" Derrida writes in Specters of Marx $(1994,5)$. This uncertainty makes their impact on the present more effective and even amplified, mostly because they are hard to notice, and, therefore, to recognize.

Moreover, as Andrzej Marzec (2015) suggests in his interpretation of Derrida's notion of hauntology, thanks to its unstable state of being/non-being, a specter's identity is something that can freely be changed. Specters have the ability to appear in the guise of different ideas, object or subjects. However, this kind of transformation comes with a price, and has a deep impact on the very core of the thing's existence: the impersonated thing loses its clear boundaries and identity, which become blurry. The stability of wellknown ideas, subjects and objects grows disturbed, and their meaning keeps changing. None of them can be trusted anymore to stay as they are forever. Therefore, we cannot be sure if they are something we can rely on (Marzec 2015, 126-127). This is a power that specters have over reality: things haunted by specters also reflect the state of the haunted present itself and can easily become heterogeneous and incoherent.

Ghosts that the player meets in the video game environment seem to share a number of common elements with Derrida's specters, even though they differ among themselves both in background story and function during gameplay. Some of them can be very central characters to the fictional world of the game, around which the whole story is built. They can not only be linked to a protagonist, as in the case of Aiden from Beyond: Two Souls (Quantic Dream, 2013) that is an entity that exists inside the main player-character, Jodie Holmes, but can even be the main hero of the story, like Ronan O'Connor from Murdered: Soul Suspect (Airtight Games, 2014).

In some fantasy role-playing video games, such as The Witcher series (CD Projekt RED, 2007-2015), which I have already touched upon, or the Dragon Age series (BioWare, 2009-2014), players can find side quests that are about ghosts. More frequently, ghosts act either as the main antagonist, like Alma Wade from the F.E.A.R. series (Monolith Productions, 2005-2011) or Blinky, Pinky, Inky and Clyde from PacMan (Namco, 1980), or as a swarm of simple, mindless enemies that the player has to eliminate to succeed. Sometimes, ghosts are nothing more than an aesthetic feature of the game environment, like the shadows in Elkhorn Mine in Kentucky Route Zero (Cardboard Computer, 2013-2016). Other occurrences appear to have no relationship with the plot at all. For instance, the ghost of a murdered man that emerges in the mirror in Hitman: Contracts (IO Interactive, 2004) is the only spirit that haunts the main character, and yet was not even his victim. The episode of finding the scene of his murder may not be part of the main story, but it still influences the player's interpretation of this character by adding an element of the uncanny to it. 
The uncanny element of video game specters is not always related to their wraithlike appearance. In some games, like, for example Oxenfree (Night School Studio, 2016), ghosts are hiding underneath a noise and glitch aesthetic that is not restricted to a single ghostly figure, but, rather, infuses the whole of the game environment. This could be understood not only as a reference to "haunted media" - such as the EVP (electronic voice phenomena), but also as a deliberate aesthetic measure to keep the player in a state of uncertainty. It begs the question of what is really haunted: is it the fictional world being depicted, or the game object through which it is depicted?

The uncanniness of a game specter can sometimes also stem from our sense that we, as players, do not have control over them. This is the case in The Sims 2 (Maxis, 2004), in which some deceased Sims can apparently decide to return from the afterlife to haunt the living ones, without the player having any say in the matter. However, in the latest games from this series, they can be tamed and become the part of the player's household, to the point that ghost babies can be born - which seems to literally 'domesticate' the idea of the uncanny, and put it in a different, more humorous perspective.

Regardless of their role in the gameplay, ghosts are all caught between two different states of existences - the semantic level and the level of digital materiality — and can never fully adopt either without the risk of losing their symbolic or gameplay functions. This paradoxical situation results from the construction of the video game object as a playable artifact (cf. Leino 2012) that creates new meanings during gameplay (Janik 2017). As I have argued elsewhere (Janik 2018), the video game object is not a stable entity with fixed features. It is being shaped in a process of play, when the game and the player meet. The process of play is, in fact, a negotiation of boundaries between those two agents. Both the video game object and the player are in a state of a constant becoming, where both of the aforementioned levels have an equal chance to manifest for one moment and let the other one shine more in the second. But both of them are always present - like two sides of the same coin.

On the semantic level, as a part of the fictional world conveyed by the game, ghosts preserve the spirit-like characteristics that are often featured in other cultural texts. They are treated as ethereal spirits, haunted souls or just the protagonist's hallucinations. They can even bend the character's perception of the surrounding reality, as is the case with Alma Wade in the F.E.A.R. games. Their immateriality makes them different from the vast majority of other items and characters that the player encounters in the game environment. Their supernatural characteristics are confirmed by the process of interpretation inside the heuristic circle of gameplay that both the player and the game are part of (Arsenault and Perron 2009). For the sake of the depth of the fictional world that is explored by the player, ghosts, like other objects in the game world, are assigned representational significance. This is how digital ghosts become uncanny beings that we can be afraid of. 
On the digital materiality level, on the other hand, the digital representations of ghosts can have a discrete, finite set of observable properties just like any other in-game object - in the same manner as other non-player characters (NPCs), useable weapons or interactive pieces of furniture. These representations are no different from any other type of programmed object that is a part of the game environment. Despite their depiction as ghostly, often transparent appearances, suggesting the illusion of an unearthly background, they exist as real in-game objects. They have not appeared in the game world as a manifestation of supernatural forces originating outside the game world, but as a part of the same ontological domain as other entities.

As in-game objects, then, ghosts have specific programmed behaviors that differentiate them from other objects, especially from other anthropomorphic figures. Sometimes their actions are more erratic: they can walk through walls, vanish into thin air or remain insensitive to the player's blows, often manifesting features that in the case of any other character might be perceived as glitches.

However, they are still bound to the software behavior and its boundaries. A good example of this tension between the ghostly character of the fictional figure and its digital materiality can be found in aforementioned Murdered: Soul Suspect. The same mechanisms that allow the player to walk through walls and possess other creatures and objects as the ghost of main protagonist, Ronan O'Connor, block her from freely exploring the gameworld. O'Connor is restricted from visiting special places and passing through certain objects. These restrictions are somewhat explained on the level of fiction. The player is informed that these special areas and objects are either consecrated or belong to the spirit world - hence she cannot use them freely. On the materialontological level, however, this clearly serves to mask the limitations of the game environment through the implementation of conveniently-placed obstacles that we cannot walk through - even as a vengeful ghost. This tension between the materiality of the digital game object and the layer of the fiction put the ontological status of video game ghosts into question: they are indeed "neither soul nor body, and both one and the other" (Derrida 1994, 6). If the player chooses to treat them in the same way as any other digital object in a game, ghosts will lose their defining feature - their uncanniness. However, if she focuses on their ghostly traits, she will accept them as beings haunting a fictional world. If ghosts were to exclusively remain a part of the fictional world, they would be excluded from the actual digital plane of existence. Thus, by favoring one option over the other, the player will change their original state of being. In fact, this double structure forces a player to constantly negotiate the ghost's meaning and state of being in order to keep its spectral (in the Derridean sense) nature intact.

This aspect of the specter, which keeps reality in the state of a constant negotiation, is in a way also close to the philosophy of Karen Barad. In her text on hauntology (2010), she points out that the future and the present do not develop linearly, but are 
intertwined. The biggest problem of the present is that it cannot be said to be happening here and now, because at the very moment, when we think about the present, it has already been tied to a certain past and a certain future. Barad understands time as something that cannot be preserved and perceived in one specific form. It is in a permanent state of disjointedness and takes on a certain form (joint) only in the moment of an intra-action (Barad 2010, 243-245). Intra-actions are the material-discursive practices that shape reality. They not only connect certain phenomena, but, what is more important, shape them into specific entities and define their properties (Barad 2007, 139-142). They are together-apart, always connected but autonomous, in a state of constant performative meeting (Barad 2014, 168-187). When an intra-action takes place, a moment in time is determined. This does not mean, however, that the set of consecutive activities is being separated, but rather one event that is not homogeneous is being shaped. For Barad, time is a phenomenon that defines and determines its own boundaries - hence it is being haunted by itself. The past, the future and the present are intertwined, to the point where they cannot define themselves unambiguously (Barad 2010, 243-245).

\section{Spectral Past in Video Games}

Thinking about the figure of the ghost means thinking about the past it belongs to. However, how exactly does the spectral nature of video game ghosts mark the notion of the past in video games? Does their uncanny (haunt)ology of being "no longer" and/or "not yet" (Hägglund 2008, 82) resonate with the place and time they choose to appear in? Both Martin Hägglund (2008) and Mark Fisher (2012) point out that time and its characteristics are very important in Derrida's work, and cannot be neglected when talking about specters. Fisher (2012) emphasizes the fact that spectral haunting is only possible "when a place is stained by time, or when a particular place becomes the site for an encounter with broken time” (p. 19), and that, in this way, the homogenization of time and space in contemporary culture can be resisted. This type of "broken time," it seems, can be found in the video game object as well. To make this point, I shall now shift my focus from the figure of the video game ghost to the spectral nature of the past in the game environment.

The situation with the past in video games is not a clear one. By analyzing the video game environment, at least two kinds of the past can be distinguished. The first one is connected to the fictional world of the game. It encompasses all the facts, artefacts and stories about the fictional world that together form its history. The player can learn this from different forms of embedded narrative (Ryan 2005; Jenkins 2004): she can read in a library-like in-game database, find hints through the exploration of the game environment, talk to characters she encounters, and so on. Clara Fernández-Vara (2011) calls this type of storytelling indexical. As players, we uncover clues relating to previous events, and put them together in order to retrace or compose the story. What is special about this kind of storytelling is that these hints (indices, as Fernández-Vara calls them) 
have "a relation to the event" and "often [are] the consequence of it" (Fernández-Vara $2011,5)$. She uses the notion of the indexical storytelling to distinguish between two senses of past inside the video game: the history of the game world and the history of the player. The first consists of all traces left for player in the game environment, including diegetic and extradiegetic objects, that point to events that happened prior to the player's engagement with the game world, also including traces of previous players. According to the second sense the history of the player is everything that the player leaves behind or changes in the game environment to construct her own story.

What seems to be problematic in this approach is the unclear distinction between the game world and fictional world - a distinction Fernández-Vara seems not to make. As Kristine Jørgensen points out, one cannot put an equality sign between those two concepts, because "even though gameworlds often may involve fiction, this does not mean that they are always and by definition fictional worlds" (2013, 5). The game world (or gameworld) is a space full of props that, in the process of play and interpretation, can become a fiction in the player's mind. Therefore, when we speak about "the remains of other agents (...), who have inhabited the space before the player arrives” (FernándezVara 2011, 7) - for instance, when we speak about the ghosts in BioShock - we need to specify whether we are talking about the ghosts that, in the fictional world, actually appear before the protagonist Jack's eyes, or about digital anthropomorphic objects placed in the game environment by the game designers. The ontology of the game object tells us that these are two different types of past: the past of the game world and the past of the fictional world. From one perspective, the latter is only a substitute for the real notion of the past in a video game object, because, in fact, the past that is being represented inside the game environment through the fictional layer never happened before the player's first appearance in the game. Ghosts from BioShock were never living humans - they were put inside the game environment as always already dead. However, we also need to remember, that these two senses of the past are constantly overlapping with each other - and the spectral nature of the past inside the video game object is produced within this overlap.

It seems that the game world's past, present, and future are produced almost simultaneously, according to a simple scenario: the player enters the video game environment, gathers some information out of which she creates a mental image of the past, and, on that basis, performs some actions that push forward the development of the story until the game ends. We can observe this both in the case of games that have linear and nonlinear structures of narration and design. In both cases, all paths lead, in fact, to one conclusion that was programmed in advance (different endings that the player can get, are from this point of view also thought in advance). Different endings that players can achieve do not appear spontaneously. On the contrary, they are all planned and programmed in detail beforehand. They all pre-exist in the materiality of the game object, 
waiting to be determined by the process of play. One can say that both types of past the one that belongs to fictional world and the one embedded inside the game world overlap with each other and, by doing so, determined the action of the player and the materiality of the game object (i.e. what is the final outcome of the game). The end of the game is not certain and waiting for the intra-active relation between the game and the player to finally determine itself (cf. Barad 2010, 251). In a sense, this double past is not only developed, or defined, at the same time as the present is, but also influences the future end of the game.

This clearly resonates with the concept of hauntology, especially in the case of the non-linear narratives of computer role-playing games, like, for example, the first trilogy of the Mass Effect series (BioWare, 2007-2012). The player not only uncovers some long-forgotten mysteries, learns from them and then makes a choice that changes the future of the fictional world. These choices stealthily travel with us through the whole game, and even from one game to another across the series, inside the rewritten code, to manifest their influence all the way to the very end.

This is especially visible during the final part of the Mass Effect series, in which our past decisions and alliances, carried over from previous games, reshape the final outcome of the battle. Based on how much support we received, new endings are unlocked to choose from. Even if the player has played only the last game in the series, she has to conform to some default choices. The past that she has not experienced haunts the future. This is the moment when the past of the fictional world intersects with the past of the game world, which is directly connected with the human presence in relation to the properties of the video game object. However, it is not only restricted to the changes on the fictional layer, like the behavior of NPCs towards the player, but also strictly on the materiality of the video game object. This is especially visible when we import old saves from previous games in the series: we have different dialogue options available, different characters appear, and our Shepard might even look different than other digital models. The latter is quite a special visual sign of the haunting of a game by the digital materiality of an earlier game in the series, due to the conflict between the graphics assets in different installments in the series.

Interestingly, the presence of a spectral past which affects the fictional world of the game also affects players who have not imported previous game states and must use the default settings. In this case, the player has often not even experienced the events that occurred in earlier games in the series. Nonetheless, these old stories and premade choices still haunt her future in the game, as well as the future of the game object itself.

These examples show that the past of the game world and the past of a fictional world in the game occur simultaneously, and although they are separate phenomena, they cannot be separated. As such, the term 'past of the game world' encompasses a different meaning here than Fernández-Vara's 'history of the game world', which, as I have 
already pointed out, refers to the past of the fictional world preceding the player's arrival. The past of the game world is associated mostly with human presence in the game environment, and especially all traces that the player leaves behind during their exploration of its space.

Carrie Heeter (1992), while analyzing virtual environments, defines this kind of presence as environmental. The game space gives signals that it is aware of the player's actions. It can be manifested in different ways. For example: the player's avatar casts a digital representation of a shadow, leaves digital footprints or bloodstains after battles, and so on. Another interesting manifestation of the game world past, which is also linked with environmental presence, is when the game records the player's gameplay and displays it later. This is the case, for instance, in Dark Souls (From Software, 2011) and Dark Souls 2 (From Software, 2014) where the player can touch a bloodstain and witness the ghostly display of the death of other players that followed this path before. However, this type of past is not only linked with very visible environmental traces or recordings of player actions. It can also be connected with the player's ability to make decisive choices that influence the history of the fictional world. In most cases, this action becomes invisible precisely because of its connection to the fictional dimension (therefore, we can observe this as a situation in which the two types of past overlap with each other).

The game world past is invariably associated with the act of play itself, and, because of that, appears to be closer to the traditional notion of the past than past of the fictional world - mostly because it actually happened and it is not an illusion. This is the past that has been created by acting within game environment. All present agents - the player, the game mechanisms, the in-game objects etc. — work together to create a given space-time situation.

Another interesting example that is somewhat connected to the past of the game world is the saving mechanism, which allows the player to return to the game environment at a specific point in time. In the moment of return, the past of the game object and the past of the fictional world are erased, but their specters remain. On the one hand, the player may have other save files that happen in the "future" in relation to the restored game state - this means that there are other game states with potentially different, undetermined endings. On the other hand, we usually go back to previous saves because something didn't go as we thought it would - for example, we made a wrong choice, or there was an error in the game making further play impossible. Nevertheless, both the player and the game object are still haunted by the past. If we have made the wrong choice and we have loaded a previous save to fix it, our new actions are clearly inspired by the past, which has "not yet" materialized and "no longer" exists. The player already knows how to behave, because she has already experienced this situation before. Time is literally "out of joint". 
This also happens in the case of death loops, like the one described by Olli Tapio Leino (2012), in which he could not cure his avatar's poisoned state no matter how many time he loaded the recent auto-save that the game object made for him. The only way out of this surreal situation was to go back almost to the very beginning of the game, which meant losing most of his progress. Knowing the past future, Leino would certainly save the game state more often and take the appropriate medication with him, and, for sure, he would not carelessly push himself into the embrace of radioactive scorpions. Even if these two types of the past - the fictional world past and the game world past — seem to overlap with each other, they often intertwine outside the player's conscious thoughts.

The past of the fictional world hides the problematic dualism of the game environment in which fiction fights with the materiality of the digital object. They both make the gameworld feel more complete and deeper, but at the same time, they try to cover its incompleteness. As the player traverses the city of Rapture, for example, the traces of her own presence - items she drops, the corpses of enemies she kills, and so on - are mixed with the staged props that create the illusion of an abandoned, unsettling place. By building up the fictional past, however, the illusion of a complex world exhibiting a temporal dimension that is not limited to the player's engagement with it is established, concealing the digital nature of the video game object.

In the next section, I would like to focus on particular examples of ghostly characters that haunt video game worlds, to show how the past of the fictional world and the past of the game world overlap with each other, creating a "broken time" that is "out of joint”, and, thus, a space of possible haunting. By doing so, and focusing on the ways in which these video game ghosts reflect the uncertain ontological status of the Derridean specter, I will show what the presence of these ghosts in the video game environment can tell us about the nature of the video game object itself.

\section{Haunted Environments}

In this section, I shall focus on examples of spectral figures in BioShock, Dear Esther (The Chinese Room, 2012), Braid (Number None, Inc., 2008) and Assassin's Creed: Revelations (Ubisoft Montreal, 2011). These figures exist somewhere in between fiction and the game mechanisms: some are hiding behind the aesthetics and putting some new light on the interpretation of the fictional world, as well as the game world; others are the significant part of the gameplay mechanisms and uncovers the digital nature of the game object. The examples from these games are not, of course, representative of any kind of final and definitive classification of in-game ghosts. Although all of them have a common theme - the anthropomorphic nature of their manifestation - they represent different approaches to the idea of the past and spectral presence inside the video game object. All of them combine the levels of fiction and digital materiality very smoothly, 
and they require a hauntological analysis to reveal what they tells us about the digital game object.

Ghostly figures appear in the video game environment as traces of the bygone that can act as 'memory discs' - they store the memory of the fictional world and are inserted to the game world by designer to be re-read by player. They create an illusion of the fictional world's historicity, and, by that token, they expand the sense of the completeness of the world. Therefore, the digital places that they haunt gain memory, which is a property that, though associated with the fictional level, might also support the game mechanics. With the sense of the uncanny accompanying the appearance of ghostly figures, it is easy to overlook the fact that they appear at pre-designated locations and can guide the player through the space of the game. They can be like a lighthouse that assures the player that she is heading in the right direction, or that the place that she has found is significant for the further development of the game state, the plot, or the interpretation of what is happening on screen.

This mechanism of being a guide for the player has been applied for example in BioShock, which I have mentioned earlier. Due to his mutated genes, the game's protagonist, Jack, has visions of the leftover memories of the late residents of Rapture. In the beginning of the game, the ghosts seem to be simple unquiet apparitions from the underwater city. However, as the plot thickens, their status becomes more problematic. We eventually learn that they are not ghosts that haunt the given place, but Derridean specters that haunt the mind of the protagonist. It is not exactly clear to whom those memories belong - perhaps they come from the people that we see in the visions. Even though they are shown from a third-person perspective, some scenes seem to be too intimate to have had a witness. Others may be witnesses' memories. However, there is also a possibility that some of them could have been instilled in the main character after the first ADAM injection. In the game's fiction, ADAM is the substance that changes cells and give humans various special abilities. A side effect of this compound is its ability to retain memories when it is removed from one person and re-injected into another. These transferred memories can be also manipulated or tinkered with in order to fill up a person with new, altered or fake information. Thanks to the ADAM that has been injected into him, the past is relived inside Jack's consciousness, creating the very subjective version of the history of Rapture we see as players. In this context, the BioShock ghosts are not just a riddle that the player needs to solve by gathering the pieces of the indexical storytelling puzzle. In Derridean hauntology, as Colin Davis (2005) points out, ghosts are "the structural openness or address directed towards the living by the voices of the past or the not yet formulated possibilities of the future” (p. 379). Past events, or rather the memories of them, are positioned alongside the present, and in Bioshock they lead the player and the character to the end of a story. 
However, I pursue this interpretation further, because these ghosts are not the only specters that affect the protagonist. Jack, who was genetically programmed, is forced to unconsciously follow orders whenever he hears the words "would you kindly...”. His past, which in the game's initial sections he is not yet familiar with, influences all his current movements. Moreover, this mechanism also has an effect on the player, as it uncovers the fact that most of the player's actions and important decisions were determined long before she has entered the gameworld. In this situation, a subversive plot twist not only points to the fact that that we as a player also are bound by the rules of a game - but also exhibits to the spectral nature of the past of the game world. The game mechanisms, covered here by the fictional layer, are acting like Derridean specters. To further follow Davis's thought about ghosts, they are an unspeakable secret in the beginning, not because they are taboo, but because they "cannot not (yet) be articulated in the languages available to us. The ghost pushes at the boundaries of language and thought" (Davis 2005, 379). In this case, the haunted game world slowly teaches the player how to use its language, to unveil at the end that it was not only Jack who was the puppet, but also herself. With this example, we can delve more into the nature of these spectral figures and their functions in the digital materiality of the game object.

Another spectral function that ghostly figures can perform in the video game environment is to mark the result of the player's additional activity and her presence in the video game. The platform game Braid, with its incorporation of time manipulation as a primary mechanic, provides us with the perfect example of such a function. On the level "Time and Decision", a shadow of the player appears when she rewinds time and for a moment both avatars (past and present) work together to solve the puzzles. It is only thanks to this multiplied self-presence that the player can finish that level. The transparent figure of the past protagonist from Braid is not just a memento of something that has passed away, but visible evidence of the player's past action. Moreover, the protagonist's shadow is not only a remainder of the avatar's body, but also inherits some abilities from the player. The power that was first assigned to the player is transferred to her shadowy image. The procedure of transferring power from an avatar to its mirror image resembles the situation described by Hans Belting, in which imprints of the body such as the Turin Shroud bearing the imprint of Jesus - are perceived to partially share the affordances and powers of the original body (Belting 2012, 55).

The example from Braid shows that the game is something more than just the space in which the player can fulfill her desires, shaping it freely with her will. At the moment of their encounter, both the game and the player change their ontological status. They become a new unity - a notion we can theorize by means of the concept of the bioobject. This idea was suggested by the Polish theatre director Tadeusz Kantor (2004, 396-406) as an attempt to describe the extraordinary relation between an actor and a stage object, which in this case is not just a simple prop or decoration. Kantor connected 
his actors with specific — sometimes quite complex — objects, merging them in a human-non-human hybrid. In his theater, objects could be an element of a specific persona, or they could even organize the whole space around them. In every case, they would cocreate the matter of the spectacle (Kłossowicz 1991, 31). By using these objects and giving them life, actors become their living part. Neither object nor actor can sustain their function on the stage without the other: the actor cannot play her role, and, in this situation of the abandonment, the inanimate object becomes a wreck (Kantor 2004, 396406).

However, importantly, the actor and the object do not lose the character they have prior to their being brought on-stage: the actor remains human and does not transcend her human condition; meanwhile, the object retains the same aesthetic qualities that Kantor called "poor" - the quality of being free from any functionality that was previously imposed by a human (Janik 2017). This quite unstable unity is not a part of the fictional content of the play, but rather, as Kantor put it, is connected to its materiality (Kantor 2004, 397). In his works, he focused mostly on the material side of the theater, and even the script of the play was treated by Kantor as another ready-made object to be incorporated in the theatrical production. It was not the goal of the theater play, but something that can be worked with, another part of the materiality of the spectacle (Święcicki 2007, 218). Fiction, as much as Kantor did not want it to be foregrounded, could always appear when the bio-object is at work: "thanks to the 'life' of these bioobjects the fiction (content) of the drama 'shows through', constantly going astray and returning” (Kantor 2004, 397). Therefore, a bio-object's structure exists independently from the play and has an autonomous character (Janik 2018).

I argue that this situation in the stage play bears enough parallels to the player's engagement with the video game object that Kantor's concept of the bio-object could be usefully applied to conceptualize the relation between the player and the game - mostly because they are both based on a connection that constantly and dynamically shapes the human and non-human agents engaged in it (Janik 2017). Even if this connection between the game and the player is a constant during the process of play, it sometimes remains transparent, almost invisible to the player's eyes. We do not think about it we focus on the outcome of our action in the game environment. However, this outcome is only possible exactly because of the connection between the player and the game object. Inside the bio-object, there is a power struggle that resolves in the creation of meaning-generative tension (Pleśniarowicz 1990, 34-35). This is the most important characteristic of the bio-object, and, when applied to the relation between the game and the player, it helps us understand the various processes of the production of meaning during the activity of play - from basic interpretations of what is expected of the "implied player" (Aarseth 2007; Janik 2018) to subversive strategies of transgressive or counter-play, like for example, glitches (Janik 2017). 
In this context, the shadow-like imprint from Braid is a reminder of this kind of connection in its subtle form. As I mentioned before, usually, during her gameplay experience, the player is not fully aware of the dualistic nature of her relationship with the game object - that, in fact, they both influence each other to create new meanings. This transparent figure of her own past gameplay is evidence of the present bond. Moreover, it is also a Derridean specter: her past activities haunt her current game session, and are able to actively shape it - after all, the player needs to synchronize with them to successfully complete this level. The future was already set in motion, before the player even realized it. However, the nature of this shadow-like figure has changed: on the one hand, the shadow can still influence the reality of the game environment and its materiality, but, on the other hand, it is only a recording - a trace of the player's actions. The player does not have control over it - she has to comply with its actions that are no longer hers. And yet - she is still part of the same bio-object as she was in the moment when the shadow-like figure was created. Again, we can look at this situation from a hauntological perspective: our shadow is and is not us, just as the specter is "neither soul nor body, and both one and the other” (Derrida 1994, 5).

A similar type of uncanniness manifests itself during the moment of the encounter of Ezio and the ghost of Altair in Assassin's Creed: Revelations. Again, two different layers of the past meet and make time "broken" or out of joint. On the fictional world level, in the moment of need, Ezio is visited by the ghost of his distant ancestor, who shows him the way through the Masyaf stronghold. Without the encasement of the narration, it can be understood as a moment in which two bio-objects are facing each other: the present one, the one that consists of the player and the game object, is led to its final destination by the second - the specter of the designer's intention.

What is interesting in both Braid and Assassin's Creed is the meaning hidden beneath the aesthetic transparency of the ghostly figures. Every specter for Derrida is "the visibility of the invisible" (Derrida 1994, 125), which means that they are the visibility of something that is hiding under the spectral characteristics (Löffler 2015, 2). In the aforementioned cases, it is the game mechanisms that are visibly invisible, masked by the fiction that presents them. Moreover, we are also under the influence of the visor effect: the specters can look at us, but we cannot return their gaze, because there is no one to see (Derrida 1994, 6). The term was coined based on the visor worn by the ghost of the dead king in Hamlet, thanks to which the specter could look, while not being visible. We cannot tame the force that we cannot see, but the force can still manipulate us _ just like we cannot shake off our ever-returning cultural heritage (Marzec 2015, 207), and that, as a result, "we inherit the law" (Derrida 1994, 7). In this way, specters control us by haunting our present. It is especially visible in the case of the ghost of Altair, when we would see past the fictional level and focus on the past of the gameworld. In this sequence, the character of Altair exists in order to literally lead us to our destina- 
tion. We cannot rebel if we still want to progress with the game. This way, a part of our autonomy, as players, is given away - we have to obey the rules. We are looking at him, while he is looking at us, but we will not get any answers, because he is nothing more than a spectral manifestation of the designers' intentions.

While in both Braid and Assassin's Creed the ghostly figures have a definite gameplay function, the ghosts in Dear Esther are motionless, silent figures. The player, during her exploration of the space of Dear Esther, can sometimes see strange shadows, but only with the corner of her eye. These transparent figures cannot be approached. They vanish immediately the very moment the player focuses on them. It is not certain who or what they are. They can be the departed souls of the long-gone islanders, or recordings of past journeys that took place before the player's arrival. The island may also represent the netherworld, and all the shadows are its inhabitants. One way or another, all those readings are based on a trope in which shadows are nothing less than imprints of a dead body or a memory left by someone who once existed in the world (Belting 2012, 218-221).

The ghosts in Dear Esther, in this context, seem to have only one function - enriching the fictional world by granting it historicity, opening it up for new interpretations. From the perspective of hauntology, this kind of function does not seem to be anything special - it does not really broaden our understanding of the video game object. However, when we activate the developer console and use noclip command, we see that the shadows are in fact some of the unnamed characters from Half-Life 2 (Valve Corporation, 2004). This should not be surprising, given that Dear Esther started as a free-to-play modification for the Source game engine. However, this situation tells us more about the properties of the video game object and its past. Here we have two completely different games, but one is clearly haunted by the other. The past of the game engine resonates with an echo in Dear Esther that happens to adopt the form of ghostlike figures. The integrity of Dear Esther, as an autonomous video game, is violated by the invasion of specters from Half-Life 2. They are the visible sign of the invisible presence of other traits Dear Esther inherited from Half-Life 2 due to its adoption of the Source engine. We also, as players, literally cannot look at them, because they vanish when we do. This form of game recycling does not diminish the ghosts' uncanny character - on the contrary, it deepens it. With this knowledge, Dear Esther needs to be reread - this time, it is not the past of the fictional world that is covering that of the gameworld. Instead, it is the past of the game world that reinforces a possible new interpretation of the fictional world, which now is located also in the sphere of influence of the fictional world of Half-Life 2. 


\section{Spectral Appearances and the Process of Anthropomorphisation}

The examples discussed in this paper illustrate the problem of the different layers of the past and their meanings in the video game object. What is worth mentioning is their shared tendency to feature ghosts that appear as human-like figures, or at least show signs of human behavior: they can speak, move or show the whole spectrum of human emotion. Their anthropomorphized form is important given that, throughout this process, a non-human agent becomes the medium of the human image, and, by extension, explicitly embodies a human being (Muniak 2010, 19-26).

Anthropomorphisation consists of both cognitive and motivational determinants. People, very often unknowingly, use it in various situation as they try to cope with the surrounding reality (Epley et al. 2007). One can assume that the tendency to anthropomorphize can be activated in gameplay situations, especially when the player wants to effectively interact with the virtual environment. As Epley, Waytz \& Cacioppo note in the context of psychology: "attributing human characteristics and motivations to nonhuman agents increases the ability to make sense of an agent's actions, reduces the uncertainty associated with an agent, and increases confidence in predictions of this agent in the future” $(2007,866)$.

Thus, I would like to posit the assumption that the player learns the game mechanisms quicker by anthropomorphizing a game's software. It is not without a reason that many game opening tutorials are based on a scenario in which the player's character encounters another anthropomorphic figure that communicates to him in a way that the player understands: it can be another human figure, which basically is a digital in-game object that is being interpreted as human; or a talking animal, which might not look human, but at least shares a language with the player. This allows the player to learn the mechanisms of the game, as well as letting her get used to the logic of the surrounding digital space. Additionally, anthropomorphisation also has the effect of creating a social relation between the player and some of the objects in the digital environment. This sociality addresses the need for human contact (Epleyet al. 2007, 866) and could be one of the reasons why the player often develops a bond with game characters, which seems to be the case especially in single-player games. Human beings favor sharing their adventures with someone, even if it is just a computer-generated character (Calleja 2011, 93-112), such as an extraterrestrial being that can be romanced inside the digital world, an annoying goose that was let loose, or even a simple metal cube upon which the player imposes human features like the ability to feel pain.

Whenever the player interacts with the game environment, she leaves traces of her actions, thereby forming a bond with the game object and, as a result, becoming a part of the bio-object. By changing the game object, she is being changed by the game object: her eye-hand coordination can improve, or her political worldview can be influenced (Janik 2018). This power struggle is never finally resolved, and anthropomorphization is 
one example of how the player can regain a dominant position - even if only for a moment. The in-game objects, anthropomorphized by the player, slowly convert the game environment into something familiar and well-known. This is possible because of the multiple dimensions of self-presence open to the player that is achieved not only through the traces she leaves behind, but also through the anthropomorphized forms of memory, such as ghosts. This kind of implementation of human features in the virtual environment allows the player to 'tame' the video game. However, for the sake of the player's engagement, this psychological mechanism should be hidden, which is possible thanks to the deepened illusion of the game world's completeness. By building a complex and multifaceted past, designers shroud the presence of the video game object and thus establish the ubiquity of fictional world experience.

Even if they have different functions or origins, anthropomorphized spectral imprints of the past, scattered around the game space, lead to the same result: covering the fact that the player does not only interact with the fictional world, but, above all, with the video game object. In other words, by putting on the mask of the ghost in its fictional world, the video game object creates past events that it can hide behind. Thus, the figures of ghosts, paradoxically, indicate both the absence of the past of the fictional world and the presence of the game world past that is related to the materiality of the game object. The first type seems to be haunted by the latter, which is stealthily hiding right outside the player's realization. Both of them exist side by side inside the game environment, but they rarely support each other. Nevertheless, exceptions can be found. One of these is the "new game plus" variant of a game, in which the player returns to a game that she has already finished: here, sometimes, the game communicates to the player that she has already explored this world, and that the world is very much aware of it. A good example of this mechanism, one that also bears the fictional trappings of ghostliness, can be found in Oxenfree, in which the uncanny element of the story, apart from the aforementioned glitch aesthetic, is built on the concept of a time loop controlled by bygone souls. When the player returns to the game environment the second time, glitches and radio interference appear already in the first minutes of the play session, by which the game environment informs us that we were already in this situation.

However, it is important to remember that ghostly figures such as these, which have been the focus of my analysis, are not the only source of spectral hauntings inside the game environment. They only serve to attenuate the layers between the fictional and material layers of the game, which makes haunting more visible. This includes, as I have mentioned before, the use of the same digital models in different games - as was the case with Dear Esther and its usage of assets inherited from the Source engine. Another interesting example is the well-known case of the 'ghost car' feature in many racing games, which allows players to record their best performance in the form of the titular spectral image which they — or other players — can then race against in the future. 
The player sees on the screen not only her own vehicle (or part of it), but also the vehicle of her opponent from the past. The real-time race, then, is directly haunted by the past actions, either of another player, or of the player herself in the past. However, sometimes there are extreme situations where the best recorded lap belongs to a deceased person (Riendau, 2014). We have the uncanny, but also sad, opportunity to meet again with someone we will never be able to play with again. In this case, we are not only haunted by mechanics and game functions, but quite literally by the presence of the deceased.

\section{Conclusions}

As this article has hopefully managed to show, uncanny specters can manifest in various forms in video games. The main focus was not to create a definitive taxonomy of these phenomena, but rather to highlight the complex nature of the past in video games that they bring to light. The concept of hauntology not only provides us with a tool by which this may be better understood, but also makes us more aware of the tension between fictionality and materiality inside the video game object. The analysis of ghostly figures in video games has, on the one hand, allowed me to look at this motif from a different interpretative perspective: from purely narrative functions, to those related to the game mechanics. However, on the other hand, I have also drawn attention to the nature of the relationship between fiction and the game world, and how they are both embedded in the digital materiality of the game object. By exploring different states of the past, I was able to show how the temporality of the game manifests itself when the player and the game are connected inside the bio-object. The temporality of the game is connected to its space and its processes, and all three change with every action that happens inside the game environment. The game's temporality, then, is negotiated by the performances of its various elements: mechanisms of the game, in-game characters and objects, the aesthetic-narrative layer, the player and her interpretations.

Thanks to the analysis of spectral characters, we could also observe the undetermined nature of the past in games. The past of the fictional game world and the game object are intertwined and influence each other. They intertwine to such an extent that it is only the intra-active force, that emerges when the game is played, that is able to outline their boundaries and allow one of them to come forward and the other to remain hidden: neither can fiction appear outside the materiality of the game, nor can the materiality of the game escape from the fiction that emerges from it.

\section{Games}

2K Games. BioShock. PC, 2007.

Airtight Games, Murdered: Soul Suspect, 2014.

BioWare, Mass Effect (series). PC, 2007-2012. 
BioWare, Dragon Age (series). PC,2009-2014.

Cardboard Computer Kentucky Route Zero. PC.

CD Projekt RED, The Witcher (series). PC, 2013-2016.

CD Projekt RED, The Witcher 2: Assassins of Kings. PC, 2011.

From Software, Dark Souls. PC. 2011.

From Software. Dark Souls 2. PC. 2014.

IO Interactive,Hitman: Contracts. PC. 2004.

Irrational Games, System Shock 2. PC. 1999.

Maxis, The Sims 2. PC, 2004.

Monolith Productions, F.E.A.R. (series). PC, 2005-2011.

Namco. Pac-Man. Arcade, 1980.

Night School. Studio Oxenfree. PC. 2016.

Number None Inc., Braid. PC. 2008.

Quantic Dream, Beyond: Two Souls. Playstation 3, 2013.

The Chinese Room, Dear Esther, PC, 2012.

Ubisoft Montreal. Assassin's Creed: Revelations. PC, 2011.

Valve Corporation. Half-Life 2. PC, 2004.

\section{References}

Aarseth, E. "I Fought the Law: Transgressive Play and The Implied Player”. In Proceedings of DiGRA International Conference: Situated Play, Tokyo, Japan, September 24-28, 2007.

Akutagawa, R. . Rashomon and Seventeen Other Stories. New York: Penguin Classics, 2009.

Arsenault, D. \& Perron, B. . "In the Frame of the Magic Cycle. The Circle(s) of Gameplay." In The Video Game Theory Reader 2, edited by B. Perron and M.J.P. Wolf, New York: Routledge, 2009.

Barad, K. Meeting the Universe Halfway: Quantum physics and the Entanglement of Matter and Meaning. Durham: Duke University Press, 2007.

Barad, K. "Quantum Entanglements and Hauntological Relations of Inheritance: Dis/continuities, SpaceTime Enfoldings, and Justice-to-Come.” Derrida Today, 3(2), 240-268, 2010.

Barad, K. "Diffracting Diffraction: Cutting Together-Apart”. Parallax: Diffracted Worlds Diffractive Readings: Onto-Epistemologies and the Critical Humanities, 20(3), 168-187, 2004.

Belting, H. Antropologia obrazu: Szkice nauki o obrazie. Kraków: TAiWPN Universitas, 2007.

Calleja, G. In-Game: From Immersion to Incorporation. Cambridge, Mass: MIT Press, 2011.

Davis, C. "Hauntology, Spectres and Phantoms.” French Studies, 59(3), 373-379, 2005.

Derrida, J. Specters of Marx: The State of the Debt, the Work of Mourning, and the New International. New York: Routledge, 1994.

Epley, N., Waytz, A., \& Cacioppo, J. T. "On Seeing Human: a Three-factor Theory of Anthropomorphism.” Psychological Review, 114 (4), 864-886, 2007.

Fernández-Vara, C.” Game Spaces Speak Volumes: Indexical Storytelling.” In Proceeding of DiGRA 2011 Conference: Think Design Play, Hilversum, The Netherlands, September 14-17, 2011.

Fisher, M. “What Is Hauntology?” Film Quarterly, 66 (1), 16-24, 2012.

Freud, S. The Uncanny. New York: Penguin Books, 2003.

Hägglund, M. Radical Atheism: Derrida and the Time of Life. Stanford: Stanford University Press, 2008.

Heeter, C. "Being There: The Subjective Experience of Presence.” Presence: Teleoperators and Virtual Environments, 1(2), 262-271, 1992.

Janik, J. Glitched Perception: Beyond the Transparency and Visibility of the Video Game Object. TransMissions: Journal of Film and Media Studies, 2(2), 65-82, 2017.

Janik, J. Game/r - Play/er - Bio-Object. Exploring Posthuman Values in Video Game Research. In Proceedings of The Philosophy of Computer Games Conference, http://gameconference.itu.dk/papers/14\%20-\%20janik\%20\%20gamer\%20player\%20bioobject.pdf , date accessed 23 December 2019, Copenhagen, 2018. 
Jenkins, H. “Game Design as Narrative Architecture.” In First Person : New Media as Story, Performance, and Game, edited by N. Wardrip-Fruin and P. Harrigan, 118-130. Cambridge, Mass. : MIT, 2004.

Jørgensen, K. GWI: “The Gameworld Interface”. In Proceedings of The Philosophy of Computer Games Conference, Bergen, Norway, October 2-4, 2013.

Kantor, T. Teatr śmierci: Teksty z lat, 1975-1984. Wrocław: Zakład Narodowy im. Ossolińskich, 2004.

Kłossowicz, J. Tadeusz Kantor - teatr. Warszawa: Państwowy Instytut Wydawniczy, 1991.

Kurosawa, A. Rashōmon, Daiei Film, Japan, 1950.

Leino, O.T. „Death Loop as a Feature.” Game Studies: The International Journal of Computer Game Research, 12(2): http://gamestudies.org/1202/articles/death_loop_as_a_feature , date accessed 3 September 2017, 2012.

Löffler, P. "Ghosts of the City: A Spectrology of Cinematic Spaces. " communication +1, 4(1): https://scholarworks.umass.edu/cpo/vol4/iss1/9 , date accessed 27 June 2018, 2015.

Marzec, A. Widmontologia. Teoria filozoficzna i praktyka artystyczna ponowoczesności. Warszawa: Fundacja Bęc Zmiana, 2015.

McCrea, C. "Gaming's Hauntology: Dead Media in Dead Rising, Siren and Michigan Report from Hell.” In Horror video games: Essays on the Fusion of Fear and Play, edited by B. Perron. Jefferson, N.C: McFarland \& Co, 2009.

Muniak, R.F. Efekt lalki: Lalka jako obraz i rzecz. Kraków: Universitas, 2010.

Pleśniarowicz, K. Teatr Śmierci Tadeusza Kantora. Chotomów: Verba, 1990.

Reindau, D. “Son Races Deceased Father's Ghost in Xbox Racer, Makes Internet Cry.” Polygon: $<$ https://www.polygon.com/2014/7/23/5929075/rallisport-challenge-ghost-son-races-fatherxbox> $>$, date accessed 23 December 2019, 2014

Royle, N. The uncanny. New York: Routledge, 2003.

Ryan, M.-L. "Narrative and the Split Condition of Digital Textuality.” In Videogame, Player, Text. Edited by B. Atkins and T. Krzywinska, Manchester: Manchester University Press, 2005.

Shakespeare, W. Hamlet. Cambridge: Cambridge University Press, 2007.

Święcicki, K. Historia w teatrze Tadeusza Kantora. Poznań: Wydawnictwo Poznańskie, 2007. 